\title{
Automation and the Welfare State: Technological Change as a Determinant of Redistribution Preferences ${ }^{1}$
}

\author{
Stefan Thewissen \\ Institute for New Economic Thinking at the Oxford Martin School, \\ Department of Social Policy and Intervention \\ and Nuffield College, University of Oxford \\ stefan.thewissen@spi.ox.ac.uk \\ David Rueda \\ Department of Politics \& IR and Nuffield College, University of Oxford \\ david.rueda@politics.ox.ac.uk
}

Forthcoming, Comparative Political Studies

\footnotetext{
${ }^{1}$ Significant parts of this article were written while Stefan Thewissen was a PhD candidate at the Economics Department at Leiden University. Financial support from the Leiden University Fund and the KETEL 1 scholarship fund is gratefully acknowledged. David Rueda thanks the National Research Foundation of Korea for partial support of this research (grant number: 2014S1A3A2044032). Earlier versions of this article were presented at the 2014 EPSA conference, the 2016 MPSA and CES conferences, and the CPE seminar at Oxford University. We thank all participants, and Nils-Christian Bormann, Koen Caminada, Henning Finseraas, Aina Gallego, Jane Gingrich, Kees Goudswaard, Robert Hellpap, Desmond King, Lieke Kools, Thomas Kurer, Brian Nolan, Stefanie Reher, Max Roser, Margit Tavits, Olaf van Vliet, and three anonymous revewers for their helpful suggestions. All errors remain ours.
} 


\begin{abstract}
Technological change is widely considered to be a key driver of the economic and occupational structure of affluent countries. Current advances in information technology have led to a significant substitution of routine work by capital, while occupations with abstract or interpersonal manual task structures are complemented or unaffected. We develop a simple theoretical framework for the reasons why individuals in routine task-intensive occupations would prefer public insurance against the increased risk of future income loss resulting from automation. Moreover, we contend that this relation will be stronger for richer individuals who have more to lose from automation. We focus on the role of occupational elements of risk exposure and challenge some general interpretations of the determinants of redistribution preferences. We test the implications of our theoretical framework with survey data for 17 European countries between 2002 and 2012. While up to now the political economy literature has emphasized other occupational risks, we find vulnerability to automation to be an important determinant of the demand for redistribution that should not be ignored.
\end{abstract}




\section{Introduction}

Technological change is widely regarded as one of the main drivers of long-term economic development (Romer 1990). By complementing occupations with certain skill profiles while making others redundant, it structures employment and significantly shapes the occupational structure (Goldin and Katz 2008; Oesch 2013). Technological innovations can have far-reaching social implications that differ across occupations. For Marx, technology contributed to the creation of a "reserve army of the unemployed" which allowed capitalists to reduce the wages of the working classes. More optimistically, technological change enables specialization and skill upgrading, which facilitates a move away from routine labour (Erikson and Goldthorpe 1992; Iversen and Cusack 2000; Wren (2013).

Current technological innovations are strongly connected to computer-based information technology. Its momentous implementation in the last decades has been spurred by significant real price declines in computing power (Autor, Levy, and Murnane 2003). Computers can perform routine tasks, which are well defined and repetitive, and can complement complex and more ambiguous abstract task structures. They, however, have a limited effect on interpersonal service tasks. An earlier literature on skill-biased technological change associated these developments to the significant increase in wage inequality between those with university degrees and those with a high school degree or less (Katz and Murphy 1992). More recently, technological change is argued to promote a significant decrease in the share of routine occupations that occupy the middle of the educational and wage distributions. Information technology therefore does not lead to linear upskilling of work, but rather to a process of polarisation (Spitz-Oener 2006; Autor, Dorn, and Hanson 2015).

Technological change is therefore connected to income inequality (Goldin and Katz 2008; Michaels, Natraj, and Van Reenen 2014) and, as such, it affects the political economy of industrialized democracies in important ways. Inequality is frequently invoked as an explanation for a number of crucial issues in political science. It is often considered a determinant of processes as diverse as the decline of electoral turnout (Nie and Kim 1978; Rosenstone and Hansen 1993), the increase in the support of extreme-right parties (Betz 1994), or the likelihood of political conflict (for a review, see Lichbach 1989). This article wishes to address one of the assumptions underlying most arguments about the influence of inequality on political outcomes. If inequality matters to individual political behavior, it seems reasonable to assume that it does so through the effects of income on redistribution and social policy preferences. These redistribution preferences may (or may not) then be reflected on party positions and, eventually, government policy. To begin at the beginning, the issue of whether technological change is a significant determinant of redistribution preferences is a topic in need of further analysis.

Given the pervasive substitution effects of information technology on routine occupations, we would expect individuals holding routine occupations to have strong 
preferences for nonmarket protection to insure against increased risk of employment and wage loss. The idea that insurance motivations are a significant determinant of preferences for redistribution has become prominent in the recent comparative political economy literature. While some authors mention risks resulting from technological change ${ }^{2}$ the vulnerability of concrete occupations to technological change is rarely examined directly. To our knowledge, only Kitschelt and Rehm (2014) analyze the relationship between routine occupations and redistribution preferences, but they focus on education as the key defining factor for these occupations, rather than measuring routine task intensity directly.

In this article we focus on the risks associated to technological change and argue that the degree of routine task intensity in different occupations is an important determinant of redistribution preferences. We develop a simple theoretical framework in which risk-averse individuals support redistribution because of their desire to insure against occupational hazards. We also argue that insurance preferences resulting from technological risks will be accentuated by income. We argue that income plays an intermediating role, since individuals will have more to lose from automation when their income level is higher. These arguments aim to re-examine the effects of redistribution and insurance motivations on redistribution preferences, while emphasizing the importance of a factor that has received a remarkable amount of popular attention (see, for example, Martin Ford/s Rise of the Robots: Technology and the Threat of a Jobless Future).

\section{The argument}

As suggested above, technological innovation entails occupational risks for those individuals whose occupations are susceptible to automation. Vulnerability to automation, in turn, is related to the routine tasks involved in any particular occupation. Individuals will therefore favor redistribution as insurance against the risk of automation when the routine task intensity (RTI) of their occupation is high. Below, we will further argue that this positive effect of RTI on preferences for redistribution is affected by income: RTI becomes a stronger influence on redistribution preferences when an individual has more to lose from automation (i.e., when her income is higher).

${ }^{2}$ See, for example, Iversen and Cusack who state that "most of the risks being generated in modern industrialized societies are the product of technologically induced structural transformations inside national labor markets. (...) It is these structural sources of risk that fuel demands for state compensation and risk sharing" (2000: 313). 


\subsection{Technological change as an unequally distributed occupational risk}

Current innovations in information technology are generally viewed to have strong and dissimilar effects across occupations (Goldin and Katz 2008; Oesch 2013; Wren 2013). They complement individuals with abstract or personal tasks, while individuals in routine occupations face an increased risk of being substituted by capital (Autor, Dorn, and Hanson 2015). Routine tasks can be partitioned into step-by-step rules and do not require cognitive or service skills that are difficult to automate (Goos and Manning 2007; Goos, Manning, and Salomons 2014). It is important to emphasize that routine tasks susceptible to automation might well be complex and require extensive educational training (for example, bookkeeping). Because of this, innovations in information technology do not impact occupations linearly across educational levels. In fact, routine occupations tend to lie in the middle of the educational and income distribution (Oesch 2013).

Advances in information technology have been found to significantly affect the occupational structure of industrialized democracies in the last couple of decades. Oesch (2013) finds a decrease of relative employment between 29 and 41 per cent in routine occupations in Denmark, Germany, Spain, Switzerland, and the UK from around 1990 to 2008, while employment in non-routine analytical and interactive occupations increased by 23 to 41 per cent. Michaels, Natraj, and Van Reenen (2014), using data for the US, Japan, and nine European countries between 1984 and 2004, report strong polarising effects of information technology, accounting for a quarter of the growth in relative demand towards non-routine high-skilled labour. Goos, Manning, and Salomons (2014) analyze the period between 1993 and 2010 in 16 Western European countries and show that technological change and offshoring can account for three quarters of the observed increase in high-skilled non-routine work and decrease in medium-skilled routine employment. ${ }^{3}$

\subsection{Routine task intensity (RTI) as determinant of preferences for redistribution}

In the traditional political economy literature redistribution preferences are a function of material self-interest (Meltzer and Richard 1981). The Metzer-Richard model assumes that the preferences of the median voter determine government policy and that the median voter seeks to maximize current income. If there are no deadweight costs to redistribution, all voters with incomes below the mean maximize their utility by imposing a 100\% tax rate. Conversely, all voters with incomes above the mean prefer a tax rate of zero. When there are distortionary costs to taxation, the MR model implies that, by increasing the distance between the median and the mean incomes, more inequality should be associated with more redistribution.

\footnotetext{
${ }^{3}$ See also Autor, Levy, and Murnane (2003) and Spitz-Oener (2006) for single-country studies on this topic.
} 
More recently, scholars have questioned the idea that material self-interest motivations should be limited to a measure of present income. This approach distinguishes an insurance component of redistribution preferences that incorporates an intertemporal element in material self-interest. Individuals will insure against uncertain future income levels and will therefore favor social protection when they are exposed to an increased risk of job or wage loss. As these forms of social security (such as unemployment benefits or social assistance) are redistributive. $]^{4}$ redistribution preferences for individuals exposed to these risks will be high (Sinn 1995; Moene and Wallerstein 2001; Iversen and Soskice 2001, 2009; Rehm 2009). Most insurance models of redistribution preferences integrate four elements: (i) the risk of job/wage loss; (ii) the likelihood of regaining employment; (iii) the degree of risk-aversion; and (iv) the presence of some policy that redistributes resources to those who experience the job/wage loss. Our main contribution in this article is to argue that the odds of becoming unemployed in (i) are a function of RTI.

Two articles have been particularly influential in the insurance approach to the determinants of social protection. We will contrast our reasoning to theirs. First, Moene and Wallerstein (2001) propose that insurance is a normal good, leading individuals to prefer more of it when their income rises. Assuming that individuals are sufficiently risk averse, so that the insurance motive dominates the Meltzer-Richard redistribution motive, income will positively affect preferences for redistribution, holding risk and risk aversion constant. In this model risk of job loss is a function of income: it is lower (or set to zero) for high-income than for low-income groups. Second, Iversen and Soskice (2001) argue that individuals with specific as opposed to general skills will favour insurance as protection against their investment in human capital. In their model there is a homogeneous risk of job loss across the electorate, but the opportunities for reemployment are lower for individuals who have invested in specific skills. Holding income and risk aversion constant, an increase in the ratio of specific versus general skills will lead individuals to prefer higher levels of nonmarket insurance.

Our point of departure lies closer to the Iversen and Soskice model, as we explicitly recognise an occupational hazard, independent of the level of income, that translates into higher preferences for nonmarket protection. We part ways with their argument by emphasizing that the risk of job or wage loss depends on the occupational level of RTI, instead of focusing on the effects of skill specificity on reemployment possibilities. The implication is quite distinct: given a level of income and risk aversion, the level of routine task intensity of an occupation positively affects preferences for redistribution.

While technological change has not been recognised as an important determinant of redistribution preferences in the comparative political literature, it is germane to ask whether RTI is in fact related to more traditional occupational risks. We will

${ }^{4}$ See, for example, Nelson (2012). 
show below that, empirically, the correlation between RTI and other occupational risks is low. Theoretically, they are distinct concepts as well..$^{5}$

Kitschelt and Rehm (2014) mention routine occupations in their analysis of the relationship between occupational characteristics and redistribution preferences. As we show in more detail in Appendix A, however, their operationalisation follows educational and income lines and does not capture the degree of occupational routine task intensity. Kitschelt and Rehm in fact do not argue that individuals in routine occupations favour more redistribution as insurance against increased risks due to automation. Rather, elaborating on Oesch (2006), they are interested in occupations as the source of socialization profiles. They differentiate occupations based on discretionary disposal over own work (the 'logic of authority'), and they hypothesize individuals with more discretionary space and authority over subordinate employees will find preserving material incentives to be important, and therefore will be against redistribution 6

As mentioned above, a common component of the more traditional conception of occupational risk is skills (Cusack, Iversen, and Rehm 2006; Iversen and Soskice 2001). Skill specificity reflects investments in human capital and consequently affects occupational risks. In the Iversen and Soskice approach, therefore, the distinction that matters is between general and specific skills, not whether a certain skill (be it specific or general) is routine, manual, or abstract. There are no a priori reasons to believe that the specificity of skills is related to the degree of occupational RTI. As an example, models, salespersons, and demonstrators have among the most general skills, while stationary-plant and related operators have very specific skills. In terms of routine task intensity, however, these occupations are very comparable - both are average as we will show below.

It is also important to note that the outsourcing of production and its specific effects on certain occupations is significantly connected to risk (Grossman and RossiHansberg 2008). The crucial factor is the degree to which parts of the production process can be executed abroad, and how this offshorability is concentrated on particular activities. Walter and co-authors have explored how offshorability affects redistribution preferences (Walter 2010; Rommel and Walter 2014; Walter 2017; Dancygier and Walter 2015). But here again we argue there is an analytic distinction between offshorable and automatable occupations (Oesch 2013; Goos, Manning, and Salomons 2014; Autor, Dorn, and Hanson 2015). There are occupations that can be executed abroad but require non-routine cognitive skills that are difficult to automate (like those in architecture, software developing, or statistical analysis). And there are

\footnotetext{
${ }^{5}$ We focus on some specific alternatives here, but return to this issue below, when we test the robustness of our results to the inclusion of a number of additional controls for occupational characteristics.

${ }^{6}$ Moreover, the differences across groups with varying degrees of authority are measured as dummy variables rather than by means of a continuous measure of the routine task intensity of occupations. See details in Appendix A.
} 
occupations that are routine and can be computerised but require spatial proximity (like security guards or customer service clerks). Moreover, studies analyzing the determinants of occupational structure find much weaker or insignificant effects of international trade and offshoring once the impact of technological change is accounted for (see Goos, Manning, and Salomons 2014; Autor, Levy, and Murnane 2003; Spitz-Oener 2006).

\subsection{The mediating effect of income}

The last part of our argument concerns a factor that can exacerbate the (positive) effect of RTI on preferences for redistribution. We argue that the importance of RTI as a determinant of nonmarket insurance demand will be increasing in the level of present income. If an individual has relatively more to lose from an occupational risk, then this risk will become more decisive in determining her preferences for nonmarket protection. This view is related but, again, deviates in significant ways from existing models of redistribution. As mentioned above, the Meltzer-Richard model emphasizes current income as the determinant of redistribution demand and does not consider insurance motivations. Income plays a similar role for Iversen and Soskice (2001), depending on risk-aversion and the nature of benefits, redistribution preferences are negatively associated to present income and they experience a general increase when an individual possesses specific skills (because of insurance-related reasons). In fact, the effect of skill-specificity in the Iversen and Soskice model is not income dependent, insurance motivations are expected to produce a similar increase in demand for protection whether an individual's income is high or low.

The model of Moene and Wallerstein (2001) is also connected to the argument we are presenting, since it argues that insurance is a normal good that individuals will demand more of as their income goes up. Moene and Wallerstein, however, focus on the effects of a mean-preserving increase of macro-inequality on individual demand for insurance. We, on the other hand, emphasize the greater effect of RTI vulnerability on the demand for insurance promoted by increased levels of individual income. In their model, income is positively associated with demand for redistribution. In our model, on the other hand, income has a direct negative effect on preferred levels of redistribution, but it will positively influence the effects of RTI (our risk exposure variable) on redistribution preferences.

Our theoretical expectations (and our empirical model to be developed below) therefore contain three components: (i) income, which in traditional Meltzer-Richard fashion is associated with decreasing support for redistribution; (ii) RTI, which captures risk exposure and insurance motivations (increasing RTI is positively associated with support for redistribution at any given level of income); and (iii) the interaction between income and RTI (we argue that insurance motivations become more influential as individuals have more income to lose, which implies that the effect of RTI will increase as income increases). These intuitions imply that the relation- 
ship between income (in an x-axis) and redistribution preferences (in the y-axis) would be represented by a negative slope. The influence of RTI would shift the slope higher (the insurance motivation increasing support for redistribution at any given level of income). And the negative slope for the relationship between income and redistribution preferences would be much flatter for high levels of RTI than for lower levels of RTI (reflecting the increasing influence of RTI as income grows). For the empirical model to be estimated below, (i) implies a negative direct effect for income, (ii) implies a positive direct effect for RTI, and (iii) implies a positive effect for the interaction between income and RTI.

Some scholars have argued that educational levels moderate the effects of offshoring on redistribution preferences, since high-skilled individuals benefit from globalization while low-skilled individuals do not (Walter 2010; Dancygier and Walter 2015). Other have put forward country-level institutions as a moderating factor for the effects of skill specificity on preferences for insurance (Gingrich and Ansell 2012). 7 But, to our knowledge, the individual level of income has not been considered an intermediating factor for RTI effects in existing studies on redistribution preferences.

\section{Data}

\subsection{Routine task intensity across occupations}

In the theoretical section we have argued that individuals holding routine occupations bear the risks of wage or employment loss from automation. We use the routine task intensity index from Goos, Manning, and Salomons (2014), who rely on Autor and Dorn (2013) and Autor, Dorn, and Hanson (2015). Goos, Manning, and Salomons distinguish between routine, manual, and abstract task inputs, derived per occupation from the Dictionary of Occupational Titles (DOT). The RTI index measures the log routine task input per occupation, minus the log manual and abstract task inputs, so that the measure is increasing in the relative importance of routine tasks vis-à-vis manual and abstract tasks. As the RTI index gauges the tasks structure of an occupation, the index is time- and country-invariant. Goos, Manning, and Salomons (2014) rescale these measures to mean 0 and standard deviation 1 . The index is available at the 2-digit occupational International Standard Classification of Occupations (ISCO)-88 level 8

Two additional occupational measures of the degree of routine task intensity are

\footnotetext{
${ }^{7}$ We test for the effects of these potentially confounding factors in our sensitivity analysis.

${ }^{8} \mathrm{No}$ information on RTI is available for six groups at the 2-digit ISCO-88 level. These agricultural, supervisory, and residual occupational groups are also excluded by Goos, Manning, and Salomons (2014), Autor and Dorn (2013) and Autor, Dorn, and Hanson (2015). We also have to exclude individuals in all waves for which information is only available at the 1-digit ISCO level. In total $12 \%$ of observations are excluded because of this.
} 
available. The first, from Oesch (2013), is again based on the differences between routine, manual, and abstract (or analytical and interactive) tasks. This RTI measure contains information at the 4-digit ISCO-88 level and distinguishes occupations into multiple non-routine and routine occupations drawing on Spitz-Oener (2006). These occupational categories can be combined into a dummy equal to 1 if an occupation is routine, and equal to 0 if otherwise. This dummy indicator and the continuous variable from Goos, Manning, and Salomons (2014) are highly correlated (0.73). As we have more variation for the continuous RTI index from Goos, Manning, and Salomons, we use this one as our benchmark and use the Oesch (2013) dummy as a sensitivity test. The second and highly influential measure is from Frey and Osborne (2017). It maps the forward-looking probability that an occupation will be automated, where the susceptibility of an occupation for automation is approximated using an algorithm following expert reviews. The measure is available at the 6-digit SOC-2010 U.S. coding and has a correlation of 0.61 with the 2-digit RTI measure from Goos, Manning, and Salomons (2014). As the measure is forward looking, and since we have to apply multiple crosswalks to link it to the survey data described below, we prefer the Goos, Manning, and Salomons (2014) measure and again use Frey and Osborne (2017) as a sensitivity test. ${ }^{9}$

The European Social Survey (ESS) provides us with pooled time-series crosssectional data of individual redistribution preferences. It has a standardized occupational identifier at the 4-digit ISCO-88 level for 2002-2010 and ISCO-08 for 2012. We recode the 2012 wave into ISCO-88 definitions using the ILO 4-digit correspondence table ${ }^{10}$ and use this occupational identifier to link individuals to the RTI index from Goos, Manning, and Salomons (2014). Our analysis draws on ESS surveys between 2002-2012 for the 17 Western countries for which at least two waves are available 11

To obtain a better understanding of what type of occupations score high and low on the RTI index, we postpone our definition of redistribution preferences for a moment and first discuss our operationalization of education and income. We use measures of years of education and present income (using respondents' answers to a survey question on household total net income). We transform the income bands

\footnotetext{
${ }^{9}$ The fact that our DOT occupation definitions are based on US data is a limitation of our RTI measure. Unfortunately, all the available alternatives, Frey and Osborne (2017) as well as Oesch (2013), are based on U.S. data too. Moreover, we are not first ones to apply this US-based measure to a wider set of industrialized countries. Both Oesch (2013) and Goos, Manning, and Salomons (2014) use it to analyze data from a set of European countries.

${ }^{10}$ We use the correspondence table from Ganzeboom, http://www.harryganzeboom.nl/ ISC008/index.htm. This correspondence table is based on the ILO correspondence table. None of our results change when we exclude 2012 in which the ISCO-08 coding is used, as shown in the sensitivity tests.

${ }^{11}$ Austria, Belgium, Denmark, Finland, France, Germany, Greece, Ireland, Italy, Luxembourg, the Netherlands, Norway, Portugal, Spain, Sweden, Switzerland, and the UK. We also conduct a sensitivity test where we include the Eastern European countries for which at least two waves are available, namely, Czech Republic, Estonia, Hungary, Poland, Slovak Republic, and Slovenia.
} 
in the survey's show-cards into their survey-specific midpoints, following Rueda (Forthcoming). The highest income band, which has no upper limit, is assumed to follow a Pareto distribution (Hout 2004; Kopczuk, Saez, and Song 2010) ${ }^{12}$ Selfreported household total net income is recoded into annual 2010 PPP-adjusted US dollars using exchange rate information from OECD (2014b). We equivalize the income level using the square root of the household size to account for differences in household size and economies of scale 13

Table 1 lists the occupations ranked by their level of RTI. It shows that on average non-routine occupations have a higher wage and educational level. Yet these relationships are not very strong; middle-income and middle-skill occupations have high values of RTI (see also Autor, Dorn, and Hanson 2015 or Goos, Manning, and Salomons 2014). In general, there is a relatively low correlation between the RTI index and both equivalized income (-0.13) and educational level (-0.17). General managers have the least routine occupation, a profession with above-average wage and skill level, but the second-least routine occupation is drivers and mobile-plant operators (low-skilled and low-paid). The most routine occupations are customer service and office clerks, and precision workers.

As mentioned above, existing contributions in the labour economics literature illustrate the relationship between automation and wage/job risk for individuals holding routine occupations (Autor, Levy, and Murnane 2003; Spitz-Oener 2006; Goos, Manning, and Salomons 2014; Michaels, Natraj, and Van Reenen 2014). Using ESS data we can also explore these outcomes. Table 1 is consistent with previous findings and shows that within the relatively short time period in our anlaysis (20022012), non-routine occupations (with a negative RTI score) saw on average an increase in their employment share and a higher increase in income when compared to routine occupations (with a positive RTI score).

\footnotetext{
${ }^{12}$ From 2002-2006 respondents were shown 12 categories that were the same across all countries. The waves from 2008-2012 distinguish between 10 categories (deciles) that differ per country.

${ }^{13}$ In the regressions below, we use individual income in relative terms, as a percentage of the country and wave specific mean. We calculate the mean as the mean of all individuals in the sample - not just the subset included in the regressions. For ease of interpretation, we divide this coefficient by 100.
} 
Table 1: Levels and changes in employment shares and income for occupations ranked by their level of RTI

\begin{tabular}{|c|c|c|c|c|c|c|c|}
\hline & ISCO & RTI & $\begin{array}{l}\text { Education } \\
\text { (years) }\end{array}$ & $\begin{array}{l}\text { Equivali } \\
(\$ 2002)\end{array}$ & $\begin{array}{l}\text { zed income } \\
\text { (\% change } \\
2002-2012)\end{array}$ & $\begin{array}{l}\text { Employ } \\
\text { (2002) }\end{array}$ & $\begin{array}{l}\text { Iment share } \\
\text { (\% change } \\
2002-2012)\end{array}$ \\
\hline Non-routine & & -0.68 & 14.04 & 29099 & 19.14 & 63.58 & 4.30 \\
\hline General managers & 13 & -1.52 & 13.39 & 28560 & 12.24 & 3.36 & -0.43 \\
\hline Drivers and mobile-plant operators & 83 & -1.50 & 11.13 & 20574 & 23.30 & 4.07 & -0.36 \\
\hline Life science and health professionals & 22 & -1.00 & 17.72 & 36648 & 16.01 & 2.24 & 0.95 \\
\hline Physical, mathematical and engineering science professionals & 21 & -0.82 & 16.19 & 36564 & 13.29 & 4.50 & 1.06 \\
\hline Corporate managers & 12 & -0.75 & 14.82 & 40690 & 7.27 & 7.07 & 1.55 \\
\hline Other professionals & 24 & -0.73 & 16.36 & 34761 & 17.74 & 7.06 & 1.33 \\
\hline Personal and protective services workers & 51 & -0.60 & 12.26 & 21094 & 21.52 & 10.06 & 1.40 \\
\hline Other associate professionals & 34 & -0.44 & 14.00 & 29576 & 18.94 & 10.69 & 0.11 \\
\hline Physical and engineering science associate professionals & 31 & -0.40 & 13.87 & 26983 & 29.30 & 5.36 & -0.92 \\
\hline Life science and health associate professionals & 32 & -0.33 & 14.74 & 26667 & 18.21 & 4.11 & -0.22 \\
\hline Extraction and building trades workers & 71 & -0.19 & 11.24 & 21339 & 23.03 & 5.04 & -0.16 \\
\hline Routine & & 0.89 & 11.81 & 21981 & 15.91 & 36.42 & -4.30 \\
\hline Sales and services elementary occupations & 91 & 0.03 & 10.47 & 18270 & 8.22 & 5.20 & 0.32 \\
\hline Models, salespersons and demonstrators & 52 & 0.05 & 12.37 & 22034 & 18.37 & 4.45 & 0.03 \\
\hline Stationary-plant and related operators & 81 & 0.32 & 11.67 & 25044 & 8.33 & 1.18 & -0.30 \\
\hline Labourers in mining, construction, manufacturing and transport & 93 & 0.45 & 10.68 & 20037 & -2.36 & 2.17 & 0.20 \\
\hline Metal, machinery and related trades workers & 72 & 0.46 & 11.90 & 21257 & 35.41 & 6.17 & -2.09 \\
\hline Machine operators and assemblers & 82 & 0.49 & 10.77 & 18893 & 8.39 & 3.46 & -0.41 \\
\hline Other craft and related trades workers & 74 & 1.24 & 10.48 & 18771 & 26.96 & 1.78 & -0.49 \\
\hline Customer services clerks & 42 & 1.41 & 12.71 & 25344 & 5.18 & 1.93 & 0.56 \\
\hline Precision, handicraft, printing and related trades workers & 73 & 1.59 & 12.73 & 25750 & 18.68 & 0.90 & -0.21 \\
\hline Office clerks & 41 & 2.24 & 12.98 & 25325 & 21.68 & 9.18 & -1.91 \\
\hline
\end{tabular}

Note: For non-routine (negative RTI score) and routine (positive RTI score) occupations, bold figures show average weighted values

for RTI, years of education, equivalized income, and income changes. They show the sums of employment shares and employment changes. Calculations are based on the countries for which information for both 2002 and 2012 is available (all except Austria, France, Greece, Ireland, Luxembourg, and Spain). 
Figure 1: Support for redistribution across occupations in 2002 and 2012

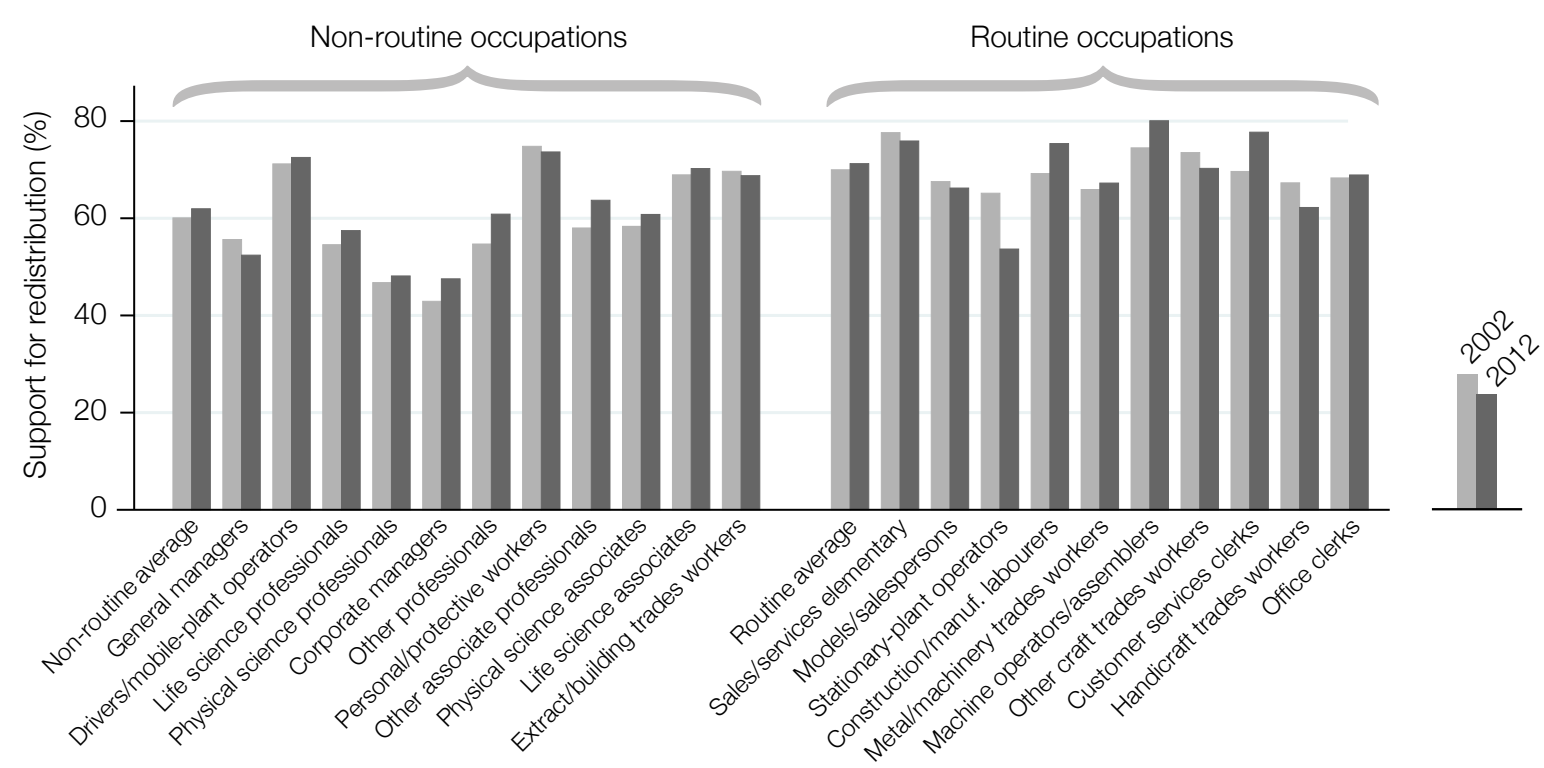

\subsection{Redistribution preferences}

The ESS contains a question designed to directly capture what we aim to explain: whether or not an individual supports government redistribution. Respondents are asked whether they agree or disagree on a five-point scale with the following statement: "The government should take measures to reduce differences in income levels." This variable is recoded to capture support for government redistribution. This question is the only one tapping into social policy preferences available in all waves of the ESS, and it has frequently been used in studies seeking to explain redistribution preferences (Rehm 2009; Burgoon, Koster, and Egmond 2012; Burgoon 2014; Kitschelt and Rehm 2014; Rueda Forthcoming; Wren and Rehm 2014; Häusermann, Kurer, and Schwander 2015).

To better illustrate the differences in redistribution preferences across occupations, we generate a binary measure for support for redistribution equal to 1 if an individual agrees or strongly agrees with support for redistribution. This variable has an overall mean of 0.65. In Figure 1 we rank the occupations on their level of RTI, again distinguishing between occupations with a negative RTI index score (non-routine, $N$ ) and a positive one (routine, $R$ ) ${ }^{14}$ The figure reflects that individuals in routine occupations have higher levels of support for redistribution. In both groups, support for redistribution increased over time.

\footnotetext{
${ }^{14} \mathrm{As}$ in Table 1, calculations are based on the countries for which information for both 2002 and 2012 is available (all except Austria, France, Greece, Ireland, Luxembourg, and Spain).
} 


\subsection{Controls}

We include a vector of individual-level controls common in the redistribution preferences literature (e.g., Rehm 2009; Burgoon 2014; Rueda Forthcoming). We include measures for years of education, age, the degree of religiosity (scaled 1-10), and indicator variables for gender, (former) trade union membership, and whether an individual is unemployed. ${ }^{15}$ At the country level, we again follow previous studies by including social spending as a percentage of GDP (Burgoon, Koster, and Egmond 2012; Rueda Forthcoming) and the unemployment rate (Burgoon, Koster, and Egmond 2012; Burgoon 2014), both lagged one year. By including ex ante levels of social spending we can account for possible diminishing marginal returns to redistribution. It could also be that higher levels of social spending affect the occupational distribution, for instance by leading to higher levels of public versus private employment. Similarly, there are reasons to believe that individuals will favour higher levels of redistribution when unemployment is high and that unemployment might affect occupational patterns.

\section{Analysis}

To account for the fact that individuals are nested within countries, we estimate a multilevel model with random intercepts for countries, and we cluster standard errors at the country level. Our dependent variable is categorical and ordered. We could analyse its determinants with ordered probit or ordinary least squares (OLS) estimation techniques. In an ordered probit model predicted probabilities are restricted to the range of the dependent variable and potential heteroskedasticity resulting from the categorical nature of the dependent variable is corrected. Some authors, however, argue that interaction effects in nonlinear models cannot be directly interpreted (Ai and Norton 2003; Greene 2010). Moreover, in a multilevel framework, the models sometimes do not converge and marginal effects cannot be easily calculated when a model contains both random and fixed terms. A linear OLS model does not have these drawbacks, and we correct for heteroskedasticity by clustering our standard errors at the country level. We estimate our main equations using both techniques. Our results are very comparable and therefore we present findings from the OLS estimations, since the interaction effects are more intuitive ${ }^{16}$ We apply design weights, which correct for the different probabilities that respondents have to be included in the sample due to the sampling design used, in all our analyses. ${ }^{17}$

\footnotetext{
${ }^{15}$ As in Cusack, Iversen, and Rehm (2006), this last dummy variable can be interpreted as a measure of realised risk (i.e., if an individual looses her or his job).

${ }^{16}$ Results for the multilevel ordered probit models are available in Appendix B.

${ }^{17}$ This is the recommended procedure by ESS, see https://www . europeansocialsurvey.org/ docs/methodology/ESS_weighting_data_1.pdf
} 


\subsection{Main results}

The results of our estimation of the effects of RTI on redistribution preferences are presented in Table 2. We present four models. The first two contain our main variables of interest (first RTI, then income) and the other two add an increasing number of control variables. Regarding the additional variables, the estimates are all consistent with previous findings in the literature. First, we find that poorer individuals favour higher levels of redistribution than richer ones. This is in line with the Meltzer-Richard model. The coefficient in Table 2 implies that a 1 percentage point increase in individual income relative to the country- and year-specific mean is associated with a 0.002 decrease in expressed redistribution preferences ${ }^{18}$ Thus, the model predicts that an individual with 1.5 times mean income has an on average 0.2 lower level of redistribution preferences compared to an individual with 0.5 times mean income, ceteris paribus. Furthermore, having less education, being older, female, unemployed, not religious, or a trade union member all increase the likelihood of agreeing that the government should reduce income disparities. Neither the country levels of social spending nor unemployment have statistically significant effects on individual redistribution preferences in our analysis.

Moving on to our main variable of interest, the results in Table 2 indicate that RTI is positively associated with redistribution preferences. This is the case no matter the number of additional variables in the analysis. This result provides empirical support for our first hypothesis that individuals in routine occupations favour more redistribution to insure against the increased risk of job or income loss.

How robust are the results for RTI presented in Table 2? In Table 3, we explore the sensitivity of the effect of RTI on redistribution preferences to a number of different specifications and additional explanatory variables suggested in the literature. We start by exploring the robustness of our results to alternative measures of RTI. We use the Oesch (2013: 156) coding to generate a dummy variable for routine occupations (model 1). Next, we apply the Frey and Osborne (2017) coding of risk of automation (model 2). Our results are replicated with both of these measures tapping into risk of automation. 19

We then explore a number of the occupational risks discussed in the theory section of this article. A first alternative is skill specificity (Iversen and Soskice 2001; Cusack, Iversen, and Rehm 2006). In model (3), we use the measure of skill specificity in

\footnotetext{
${ }^{18}$ Recall that in the regressions, we use individual income as a percentage of the country and wave specific mean.

${ }^{19}$ The original coding is at the 6-digit SOC-2010 coding for U.S. occupations. We apply the U.S. BLS crosswalk to ISCO-08 at the 4-digit level. In total 18 out of 702 occupations from Frey and Osborne cannot be matched. Due to discrepancies between correspondence tables, 166 ISCO-08 4-digit occupations match perfectly by referring to only 1 Frey and Osborne occupation; for the others we take means of the probabilities to match them to the ISCO-08 occupations. We then apply the Ganzeboom crosswalk (as we did before) to end up with ISCO-88 coding, where we again have to calculate means for the probabilities of occupations that cannot directly be matched.
} 
Table 2: RTI and redistribution preferences

\begin{tabular}{|c|c|c|c|c|}
\hline & $\begin{array}{c}\text { (1) } \\
\text { RTI only }\end{array}$ & $\begin{array}{c}\text { (2) } \\
+ \text { individual } \\
\text { income }\end{array}$ & $\begin{array}{c}\text { (3) } \\
+ \text { individual } \\
\text { controls }\end{array}$ & $\begin{array}{c}\text { (4) } \\
+\begin{array}{c}\text { country-level } \\
\text { controls }\end{array}\end{array}$ \\
\hline RTI & $\begin{array}{c}0.085^{*} * * \\
(0.000)\end{array}$ & $\begin{array}{c}0.067 * * * \\
(0.000)\end{array}$ & $\begin{array}{c}0.042^{* * * *} \\
(0.000)\end{array}$ & $\begin{array}{c}0.042 * * * \\
(0.000)\end{array}$ \\
\hline Income & & $\begin{array}{c}-0.211 * * * \\
(0.000)\end{array}$ & $\begin{array}{c}-0.180 * * * \\
(0.000)\end{array}$ & $\begin{array}{c}-0.180 * * * \\
(0.000)\end{array}$ \\
\hline Years of education & & & $\begin{array}{c}-0.022 * * * \\
(0.000)\end{array}$ & $\begin{array}{c}-0.022 * * * * \\
(0.000)\end{array}$ \\
\hline Male & & & $\begin{array}{c}-0.208 * * * * 4 \\
(0.000)\end{array}$ & $\begin{array}{c}-0.208 * * * * 4 \\
(0.000)\end{array}$ \\
\hline Age & & & $\begin{array}{l}0.003 * * \\
(0.014)\end{array}$ & $\begin{array}{l}0.003 * * \\
(0.017)\end{array}$ \\
\hline Trade union member & & & $\begin{array}{c}0.176 * * * * \\
(0.000)\end{array}$ & $\begin{array}{c}0.176 * * * * \\
(0.000)\end{array}$ \\
\hline Degree of religiosity & & & $\begin{array}{c}-0.008 * * \\
(0.016)\end{array}$ & $\begin{array}{c}-0.008 * * \\
(0.019)\end{array}$ \\
\hline Unemployed & & & $\begin{array}{c}0.137 * * * * \\
(0.000)\end{array}$ & $\begin{array}{c}0.135 * * * \\
(0.000)\end{array}$ \\
\hline Lag of social spending & & & & $\begin{array}{l}-0.004 \\
(0.503)\end{array}$ \\
\hline Lag of unemployment & & & & $\begin{array}{c}0.006 \\
(0.554)\end{array}$ \\
\hline Constant & $\begin{array}{c}3.743^{* * *} \\
(0.000)\end{array}$ & $\begin{array}{c}3.977^{* * * *} \\
(0.000)\end{array}$ & $\begin{array}{c}4.193 * * * \\
(0.000)\end{array}$ & $\begin{array}{c}4.246^{* * *} \\
(0.000)\end{array}$ \\
\hline Log likelihood & -93913 & -93176 & -92414 & -92412 \\
\hline Intraclass correlation & 0.101 & 0.104 & 0.113 & 0.106 \\
\hline $\mathrm{N}$ & 64639 & 64639 & 64639 & 64639 \\
\hline Number of countries & 17 & 17 & 17 & 17 \\
\hline
\end{tabular}

Note: Multilevel OLS model with random country intercepts and standard errors clustered at the country level. $\mathrm{P}$ values in parentheses, ${ }^{*} \mathrm{p}<0.1, * * \mathrm{p}<0.05, * * * \mathrm{p}<0.01$. 
Rehm (2009). This is a time-invariant measure available at the 2-digit ISCO-88 level. ${ }^{20}$ Burgoon, Koster, and Egmond (2012) identify migration as an occupational risk. We follow their empirical strategy and include the number of foreign born (around the year 2000) as a percentage of the population at the 2-digit ISCO-88 level (OECD 2008). We find that individuals in occupations with higher ratios of foreigners have higher levels of redistribution preferences, as also found by Burgoon, Koster, and Egmond (2012). More importantly, the significance of our variables of interest (RTI) in models (3) and (4) is not affected by including these occupational hazards. We then turn to the effects of offshoring, relying on Walter's binary index (Walter 2010, 2017; Dancygier and Walter 2015). This index is defined at the 4-digit ISCO-88 level $[21$ We argued above that RTI substantively differs from skill specificity and offshoring. This is reflected in modest correlations between these variables (0.14-0.19). More importantly, in model (5), our main results are confirmed ${ }^{22}$ Occupational risk is an important part of a general sociological conception of class and, as such, it needs to be accounted for in our empirical analysis. In model (6) we include a control for class. We use an international comparative version of the European Socio-economic Classification, based on the class categories in the EriksonGoldthorpe-Portocarero Schema (Erikson and Goldthorpe 1992). The variation of RTI within class categories is high enough to allow us to assess whether the results regarding routine task intensiveness are robust to controlling for the effects of class ${ }^{23}$ While the effects of RTI are reduced, we still find the model controlling for class to confirm our main results.

The levels of unemployment of specific occupations are directly connected to the insurance logic proposed in this article. In model (7) we include the occupational unemployment rate from $\operatorname{Rehm}(2009) \cdot{ }^{24}$ This is a stringent test, since our

\footnotetext{
${ }^{20}$ The data are from http://www . people.fas .harvard.edu/ iversen/SkillSpecificity $\mathrm{htm}$. This website also contains information regarding measurement.

${ }^{21} \mathrm{We}$ are grateful to Stefanie Walter for sharing her coding with us.

${ }^{22}$ We find in model (2) that individuals whose occupations require more specific skills favour more insurance. Interestingly, individuals in offshorable occupations decrease rather than increase their preferred level of redistribution. This finding is also reported by (Walter 2017). Walter argues that exposure to offshoring increases risk perceptions among low-skilled, whereas high-skilled (or 'globalisation winners') lower their demand for redistribution.

${ }^{23}$ While class overlaps to some extent with our RTI measure, the correlation between the two variables is quite low for the individuals in our sample (0.20). There are significant difference in the levels of RTI among classes. Interestingly, the class with highest routine task intensity is the "intermediate occupations" class (0.87). The so-called "routine" class, is, using our measure, actually not routine at all. In fact, it has on average a negative RTI $(-0.15)$. The least routine are the "large employers/higher managers and professionals" (-0.79). More importantly, there's lots of variation in RTI within classes. The standard deviation of RTI for the "large employers/higher managers and professionals" is relatively low (0.23), for the others it varies between 0.59 ("lower technical") and 1.33 ("intermediate occupations"). Our measure therefore does not track tracks blue vs. white collar (or manual vs. non-manual labor) occupations (if anything the class variable is closely related to levels of education).

${ }^{24}$ We thank Philipp Rehm for sharing his occupational information. Data for Luxembourg are missing.
} 
argument is that RTI at the occupational leads to a higher levels of job risk. We lag the occupational unemployment rates by one year as information for 2012 is missing. Unfortunately, data are only available at the 1-digit occupational level. The occupational unemployment rate and the RTI index are positively correlated (0.23) and, as expected, including the occupational unemployment rate decreases the size of the RTI index coefficient on redistribution preferences. But our main finding are still robust to the inclusion of this additional variable ${ }^{25}$ Next, we introduce a measure for the routine occupations in Kitschelt and Rehm (2014). As we explain in more detail in Appendix A, this occupation operationalisation follows educational and income lines and does not capture the degree of occupational routine task intensity. Nevertheless, the results in model (8) confirm our main findings. We continue by including a measure of deindustrialisation (model 9), as it might overlap with our RTI measure and is seen as a factor influencing redistribution preferences (see, for example, Iversen and Cusack 2000). To measure this, we include a dummy for individuals working in the manufacturing sector and our RTI estimate is unaffected. ${ }^{26}$ Authors like Rueda (2007) argue for the increasing importance of labor market "dualization." In this framework, "insiders" have stable and protected employment whereas "outsiders" have insecure jobs or no jobs at all. Since outsiderness is an important source of labor market risk, we address it in model (10). Again, our main results hold when controlling for labour market outsiderness, which is proxied by a dummy for individuals with a fixed-term contract. ${ }^{27}$

A general problem, not only for this article but for other analyses in this literature, is that occupational categories capture very different factors. This is not fully resolved by the robustness tests described above. We attempt to further address this issue in Appendix C, dedicated to explore unobserved variation across and within occupations. In addition, it is clear that occupational categories capture not only insurance related effects but also those related to socialization. We mentioned above how Kitschelt and Rehm (2014) argue in favor of the role of occupations as the source of socialization profiles. As Kitschelt and Rehm themselves recognize, it is difficult to estimate the effect exclusively due to socialization of occupational variables like RTI. We offer

${ }^{25}$ Our argument makes clear that the RTI mechanism captures risk of job/wage loss. This, however, does not imply that the effect of RTI should disappear when controlling for occupational unemployment risk. Occupational unemployment risk is a measure of realized risk in the past. It may be a good signal for individuals to predict future risk of unemployment, but it is not the only one (and it is certainly not only about RTI exposure). Moreover, it only tracks unemployment and not income uncertainty (as in wage loss or lack of wage progression), which is an additional consideration in our argument about RTI exposure.

${ }^{26}$ Further tests (available from the authors) also point out that the variation of RTI within manufacturing is comparable to the variation within non-manufacturing industries.

${ }^{27}$ There are different ways of conceptualizing insider-outsider differences, emphasizing employment status, access to benefits and protection, political representation, and citizenship (see Schwander and Hausermann 2013). We are interested in individual political preferences so we regard precarious employment (since unemployment is already controlled for) as the defining characteristic that divides outsiders from insiders. 
Table 3: Robustness checks for main results

\begin{tabular}{|c|c|c|c|}
\hline & & RTI coefficient & $\mathrm{p}$ value \\
\hline & Original result from Table 2 , column (4) & $0.042 * * *$ & $(0.000)$ \\
\hline (1) & Dummy RTI from Oesch (2013) & $0.071 * * *$ & $(0.000)$ \\
\hline (2) & Automation from Frey \& Osborne (2017) & $0.162 * * *$ & $(0.000)$ \\
\hline (3) & Skill specificity & $0.039 * * *$ & $(0.000)$ \\
\hline (4) & Foreign ratio & $0.048 * * *$ & $(0.000)$ \\
\hline (5) & Offshoring & $0.057 * * *$ & $(0.000)$ \\
\hline (6) & Class & $0.028 * * *$ & $(0.000)$ \\
\hline (7) & Occupational unemployment rate & $0.024 * * *$ & $(0.002)$ \\
\hline$(8)$ & Task groups from Kitschelt\&Rehm & $0.071 * * *$ & $(0.000)$ \\
\hline (9) & Deindustrialisation & $0.043 * * *$ & $(0.000)$ \\
\hline (10) & Labour market outsiderness & $0.036 * * *$ & $(0.000)$ \\
\hline (11) & Public sector employee & $0.048 * * *$ & $(0.000)$ \\
\hline (12) & Left-right scale & $0.039 * * *$ & $(0.000)$ \\
\hline (13) & All individuals & $0.035 * * *$ & $(0.000)$ \\
\hline (14) & Market income earners & $0.042 * * *$ & $(0.000)$ \\
\hline (15) & Imputed RTI missing groups & $0.039 * * *$ & $(0.000)$ \\
\hline (16) & Eastern Europe & $0.040 * * *$ & $(0.000)$ \\
\hline (17) & Excluding 2012 & $0.042 * * *$ & $(0.000)$ \\
\hline (18) & Before 2008 (excluding 2008-2012) & $0.038 * * *$ & $(0.001)$ \\
\hline (19) & Binary dependent variable & $0.018 * * *$ & $(0.000)$ \\
\hline (20) & Absolute redistribution & $0.042 * * *$ & $(0.000)$ \\
\hline$(21)$ & Gini market income & $0.042 * * *$ & $(0.000)$ \\
\hline$(22)$ & EPL index & $0.041 * * *$ & $(0.000)$ \\
\hline (23) & UB replacement rate & $0.042 * * *$ & $(0.000)$ \\
\hline (24) & OLS with country fixed effects & $0.042 * * *$ & $(0.000)$ \\
\hline
\end{tabular}


here some circumstantial evidence to show that the socialization (as opposed to the insurance) effect of RTI is not particularly strong. First we look at age cohort effects (if socialization is strong, the effects of RTI should be stronger for older cohorts), then we do a couple of placebo tests (RTI should predict redistribution preferences, but not other attitudes) ${ }^{28}$ In our age cohort analysis (unfortunately the ESS does not provide an indicator for job tenure so we use age as a proxy) we include an interaction between age and RTI. This is done without any control variables and with all control variables (as in Table 3) ${ }^{29}$ The interaction between age and RTI is never significant and the estimates for other variables do not change. Second, we conduct placebo tests in which we regress trust in the police and trust in the legal system on RTI. We find that RTI is not a statistically significant determinant of these attitudes.

Having addressed a number of factors that are related to occupational and labor market risks, we continue by exploring some additional individual-level control variables. In model (11), it makes little difference to our main findings if we add an indicator variable capturing whether individuals are public sector employees. Our main analysis does not include the left-right position of individuals, as we think of redistribution preferences (like, for example, Rueda|Forthcoming) as a key element of ideology. But other authors have argued for ideology as an exogenous determinant of redistribution preferences (Margalit|2011). When we include left-right self-placement as an independent determinant of redistribution preferences in model (12), our main findings remain the same.

We then test the robustness of our results to the sample definition. In model (13), we expand our sample by 65 per cent by including all individuals for which information is available (we insert an additional dummy for people not active in the labour market). Ideally, we would use gross rather than net income, but as this information is not available in the ESS, we instead restrict our sample by focusing only on those individuals whose main source of income is wages, salaries, selfemployment, farming, or capital income (model 14). Our results are replicated. ${ }^{30}$ An unfortunate element of the RTI measure we use is that information is missing for six 2-digit occupational groups. Of these groups, legislators and senior officials, teacher professionals, and teaching associate professionals are classified as non-routine by Oesch (2013) and also score low in automation probabilities in the Frey and Osborne coding. We give these occupations the average non-routine score $(-0.68$, see Table 1$)$. In model (15), we then impute the average routine score (0.89) for market-oriented skilled agricultural and fishery workers, subsistence agricultural and fishery workers, and agricultural, fishery and related laborers. These occupations are classified as routine by Oesch and have automatable probabilities above 0.67 in the Frey and Osborne coding. We find similar results, including the size of the coefficient. In

\footnotetext{
${ }^{28}$ Results available from the authors.

${ }^{29}$ We also estimate a model with an interaction with income (as in Table 5).

${ }^{30}$ Restricting the analysis to employed individuals only also confirms our main results.
} 
model (16), we test whether our results still hold when we include Eastern European countries for which at least two waves of data are available 31 We also test whether leaving out 2012, which is based on another occupational coding scheme (model 17), or leaving out all crisis years (model 18) affects our results. ${ }^{32}$

By applying OLS to a categorical dependent variable, we implicitly make the proportional lines assumption that the effect of the independent variables is constant for each answer category of our dependent variable. This assumption can be relaxed by transforming our categorical dependent variable into a dummy equal to 1 when an individual prefers or strongly prefers redistribution (model 19). This does not affect the sign and significance of our variable of interest.

We also test for robustness with country-level controls in Table 3. We again lag all these factors by one year. Support for redistribution might decrease when present levels of redistribution are high because of disincentive effects (Thewissen 2014) or because actual levels of redistribution may act as a benchmark when answering questions about whether the government should reduce income differences (Rueda Forthcoming). Alternatively, individuals may potentially favour more redistribution when existing levels of inequality are higher. We include a measure of absolute level of redistribution (model 20) and the level of market income inequality from the Solt (2014) database (models 21) ${ }^{33}$ Adding these factors does not affect the estimates of interest.

Two other country-level factors might be important as they could decrease the level of redistribution individuals favour by providing insurance (Gingrich and Ansell 2012). We include the overall employment protection legislation (EPL) index and the summary measure of OECD unemployment benefit replacement rates (OECD $2014 \mathrm{a}, \mathrm{c}$ ) in models (22) and (23). Once again, our main findings are confirmed. ${ }^{34}$ They are also confirmed, finally, when we include country fixed effects in model (24) to control for any unspecified time-invariant country-specific characteristic.

In the previous section we mentioned that, in Table 2, RTI was positively associated with redistribution preferences no matter the number of additional variables in the analysis. The sensitivity tests in Table 3 leave no doubt about the robustness

\footnotetext{
${ }^{31}$ The Eastern European countries are Czech Republic, Estonia, Hungary, Poland, Slovak Republic, and Slovenia. There are a small number of observations for which the calculation of top income levels leads to problems (becoming strongly negative) for these countries, as the number of people in the last or next-to-last income band is too low. We exclude the top income band persons in Czech Republic 2002 (two persons), Hungary 2004 (one), Slovak Republic 2004 (seven), and Slovenia 2006 (one).

${ }^{32}$ More generally, dropping countries, years, or occupations one by one does not affect signs or significance for the variable of interest (see also Appendix C).

${ }^{33}$ We calculate unweighted averages per country-year observation for our sample from the Solt database. Unfortunately, within our multilevel framework we cannot take standard errors of the levels of inequality and redistribution into account. We also conduct these tests leaving out or original country-level variables, or by using relative redistribution and the Gini for net income, none of which alters the results.

${ }^{34}$ Leaving out the original country-level variables does not alter these results.
} 
Table 4: Substantive effects of RTI

\begin{tabular}{lccc}
\hline & $\begin{array}{c}\text { Effect of standard deviation change } \\
\text { on redistribution preferences }\end{array}$ & 95\% confidence bounds \\
\hline RTI & $0.052 * * *$ & 0.039 & 0.066 \\
Skill specificity & $0.024 * * *$ & 0.015 & 0.033 \\
Offshoring & $-0.065^{* * *}$ & -0.076 & -0.053 \\
Education & $-0.073^{* * *}$ & -0.092 & -0.054 \\
\hline
\end{tabular}

of our results. It is, however, not straightforward to get an intuitive impression of the substantive importance of RTI. We attempt to do this by explicitly comparing the effects of RTI to those of other explanatory variables. We first do this with two of the other occupational risks discussed in the theoretical section (skill specificity and offshoring) by calculating the effects of a standard deviation increase in each variable and comparing these effects. We then also include education to illustrate the effects of RTI. We do these comparisons for two reasons. On the one hand, we wish to explicitly compare the effects of RTI to two of the most influential alternative approaches to the relationship between occupational risks and redistribution preferences. Iversen and Soskice's argument that individuals with specific skills will favour insurance as protection against their investment in human capital has been highly influential in the comparative political economy literature on redistribution. Emphasizing the international dimension, the offshorability of parts of the production process and its concentration on particular activities has also become an important alternative occupational argument about demand for redistribution (Walter 2010, 2017). The inclusion of education, on the other hand, moves away from specific occupational factors to address one of the most widely recognized determinants of redistribution preferences. Since Lipset (1960), education has been understood as a relevant determinant of left party support and more pro-redistribution preferences (see also Alesina and Giuliano 2009). But the relationship between education and future expected income may make these effects more ambiguous. Benabou and Ok (2001) argue that the prospects of upward mobility would make more educated individuals less likely to support redistribution than their present level of income would suggest.

Focusing on the occupational effects in Table 4, the average level of RTI in our sample is $-0.13^{35}$ and a standard deviation increase is roughly comparable to an occupational switch from extraction and building trades workers to machine operators and assemblers (-0.13 to 0.83$)$. For the skill specificity variable, a standard deviation increase is approximately equivalent to an individual switching from physical, mathematical and engineering science professionals to sales and services elementary

\footnotetext{
${ }^{35}$ Recall that Goos, Manning, and Salomons (2014) normalize the level of RTI to have a (employment weighted) mean of zero.
} 
occupations (4.2 to 7.5). And for offshoring, it can be interpreted as an occupational switch from metal, machinery, and related trades workers to general managers (0.45 to 0.95 ). An increase equivalent to a standard deviation in education would move an individual from 13.3 years of schooling (the mean in our sample) to 17.2. Table 4 suggests that a one standard deviation increase of the RTI index is associated with a increase in redistribution preferences of about 0.05 . Recall that respondents are asked whether they agree or disagree on a five-point scale and that the mean for this variable in our sample is 3.66. Our results therefore indicate that an increase in RTI equal to one standard deviation would increase by $1.4 \%$ an individual's support for redistribution from the average in the sample. To put this increase in context, this is an effect that is more than two times stronger than a comparable increase in skill specificity on the favoured level of redistribution. It is an absolute effect that is roughly comparable to a standard deviation increase in education (which is associated with an decrease in support for redistribution of about 0.07$)^{36}$ and in offshoring (associated with a decrease of less than 0.07). It is therefore the case that the effects of routine task intensity emphasized in this article are more substantive in determining redistribution preferences than one of the most influential alternative approaches to occupational risks (skill specificity). They are similar to those of a variable generally recognized as essential to our understanding of political preferences (education) and to those of a variable that has received an increasing level of attention in academic and public policy circles (offshorability) ${ }^{37}$

\subsection{Evidence for the mediating effect of income}

Having found a positive effect of RTI on redistribution preferences, we now inquire whether this relation is intermediated by income. Following an insurance logic, we argued that income would exacerbate the effects of RTI, as richer individuals have relatively more to lose from job losses due to automation. As already stated, we also argued that income itself would be negatively associated with preferences for redistribution. The results from all 3 models in Table 5 support this line of reasoning, showing a negative direct effect of income, a positive direct effect of RTI, and a positive effect of the interaction between income and RTI on preferences for redistribution.

To facilitate the interpretation of the interaction, we evaluate the effect of RTI on redistribution preferences at different levels of income in Figure 2, We use model (3) in Table 5, with the highest number of controls, for our calculations.

\footnotetext{
${ }^{36}$ Like those in Alesina and Giuliano (2009), our results support the argument for the effects of prospects of upward mobility in Benabou and Ok (2001).

${ }^{37}$ It is important to mention here, however, that Table 4 /shows the connection of specific occupations to international outsourcing to be associated with a decrease, rather than an increase, in the demand for redistribution (once the effects of RTI are controlled for). Walter (2010, 2017) discusses this topic in greater detail.
} 
Table 5: RTI and income interaction

\begin{tabular}{|c|c|c|c|}
\hline & $\begin{array}{c}(1) \\
\text { RTI * income }\end{array}$ & $\begin{array}{c}\text { (2) } \\
+ \text { individual } \\
\text { controls }\end{array}$ & $\begin{array}{c}(3) \\
+ \text { country-level } \\
\text { controls }\end{array}$ \\
\hline RTI & $\begin{array}{c}0.068 * * * \\
(0.000)\end{array}$ & $\begin{array}{c}0.043 * * * \\
(0.000)\end{array}$ & $\begin{array}{c}0.043 * * * * \\
(0.000)\end{array}$ \\
\hline Income & $\begin{array}{c}-0.201^{* * *} \\
(0.000)\end{array}$ & $\begin{array}{c}-0.172^{* * * *} \\
(0.000)\end{array}$ & $\begin{array}{c}-0.172 * * * \\
(0.000)\end{array}$ \\
\hline RTI * income & $\begin{array}{c}0.032^{* * *} \\
(0.000)\end{array}$ & $\begin{array}{c}0.026 * * * \\
(0.000)\end{array}$ & $\begin{array}{c}0.026 * * * \\
(0.001)\end{array}$ \\
\hline Years of education & & $\begin{array}{c}-0.022^{* * *} \\
(0.000)\end{array}$ & $\begin{array}{c}-0.022 * * * \\
(0.000)\end{array}$ \\
\hline Male & & $\begin{array}{c}-0.207^{* * *} \\
(0.000)\end{array}$ & $\begin{array}{c}-0.207 * * * \\
(0.000)\end{array}$ \\
\hline Age & & $\begin{array}{l}0.003 * * \\
(0.013)\end{array}$ & $\begin{array}{l}0.003 * * \\
(0.016)\end{array}$ \\
\hline Trade union member & & $\begin{array}{c}0.176 * * * \\
(0.000)\end{array}$ & $\begin{array}{c}0.176 * * * \\
(0.000)\end{array}$ \\
\hline Degree of religiosity & & $\begin{array}{c}-0.008^{* * *} \\
(0.016)\end{array}$ & $\begin{array}{c}-0.008 * * \\
(0.019)\end{array}$ \\
\hline Unemployed & & $\begin{array}{c}0.139 * * * \\
(0.000)\end{array}$ & $\begin{array}{c}0.137 * * * \\
(0.000)\end{array}$ \\
\hline Lag of social spending & & & $\begin{array}{c}-0.004 \\
(0.500)\end{array}$ \\
\hline Lag of unemployment & & & $\begin{array}{c}0.006 \\
(0.560)\end{array}$ \\
\hline Constant & $\begin{array}{c}3.744 * * * \\
(0.000)\end{array}$ & $\begin{array}{c}3.988 * * * \\
(0.000)\end{array}$ & $\begin{array}{l}4.042 * * * \\
(0.000)\end{array}$ \\
\hline Log likelihood & -93162 & -92403 & -92402 \\
\hline Intraclass correlation & 0.104 & 0.113 & 0.107 \\
\hline $\mathrm{N}$ & 64639 & 64639 & 64639 \\
\hline Number of countries & 17 & 17 & 17 \\
\hline
\end{tabular}

Note: Multilevel OLS model with random country intercepts and standard errors clustered at the country level. $\mathrm{P}$ values in parentheses, ${ }^{*} \mathrm{p}<0.1, * * \mathrm{p}<0.05, * * * \mathrm{p}<0.01$ 
Figure 2: Effects of RTI on redistribution preferences conditional on income

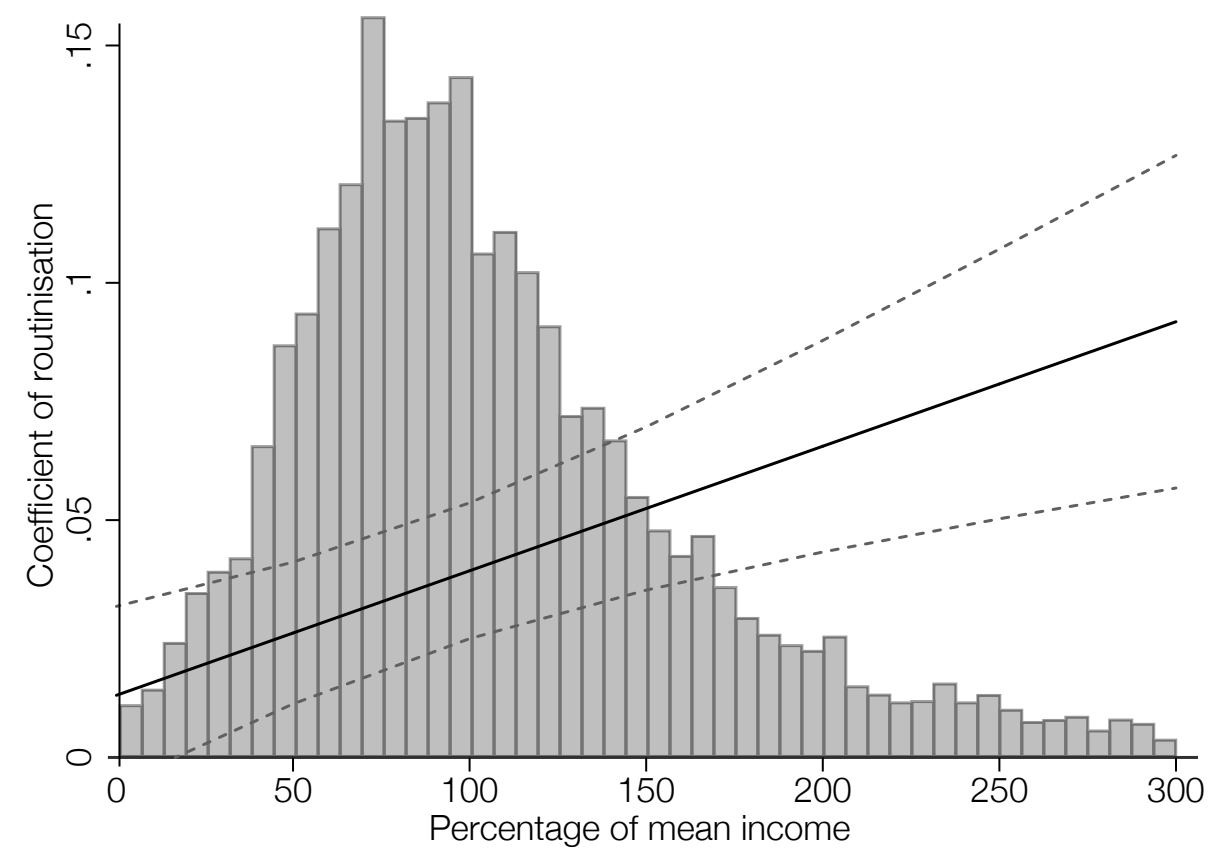

Note: Multilevel OLS model with random country intercepts and standard errors clustered at the country level. All continuous control variables are held at their mean and dummies at their median. The black line shows the coefficient of RTI on redistribution preferences (y-axes) at different levels of income (x-axes). The dashed lines are the 95 per cent confidence intervals. The grey histogram plots the distribution of observations across levels of income.

All continuous control variables are held at their mean and the dummies at their median value. The figure makes clear that the effects of RTI on redistribution preferences are monotonically increasing in the level of income. For individuals with a very low income (less than $25 \%$ of mean income), the association between RTI and redistribution preferences is insignificant. For the largest part of our sample, however, RTI is a positive and significant determinant of redistribution preferences, and this influence becomes more substantive as income grows.

We can provide a more formal test for whether the effect of RTI on redistribution preferences differs for individuals with different income levels (and we will also use this framework for our interaction sensitivity tests below). To do this, we define meaningful values of low, average, and high individual relative income. We select $50 \%, 100 \%$, and $175 \%$ of the country and year-specific mean income. These are not extreme values, $12 \%$ of the observations lie below $50 \%$ relative income and $13 \%$ of the observations lie above $175 \%$ income (and 175\% is almost equal to the median plus one standard deviation of relative income).

We can then calculate the effect of RTI on redistribution preferences for an individual with average income, having an income of $100 \%$ of the country and 
Table 6: Robustness checks for interaction results

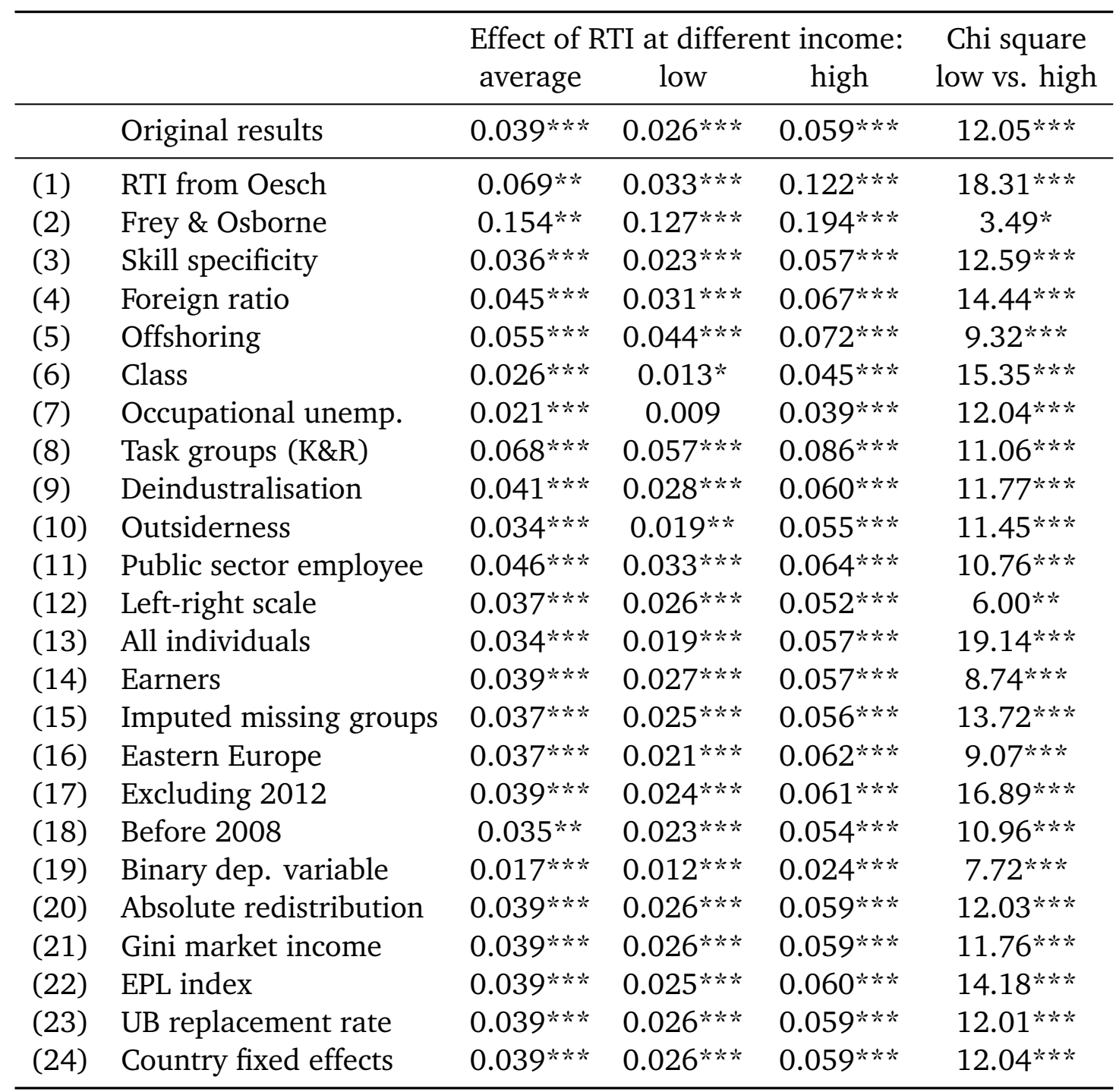

year specific mean keeping all other control variables at their mean or median values. Moreover, we can compare the effect of RTI on redistribution demand for an individual with low income to one with high income, holding everything else equal, and we can calculate a simple (unadjusted) chi square post-estimation test to see whether the effect of RTI on redistribution preferences is statistically different for a low versus a high-income individual.

Table 6 presents the effect of RTI at the different levels of income explained above. We reproduce the robustness tests described in more detail when analyzing the results in Table 3 (and with the same theoretical justifications summarized then). In all tests, the effect of RTI is significant at average levels of income. With one exception, the effect of RTI is less sizeable for individuals with low income and higher for individuals with high income (the exception being the insignificance of 
low income when controlling for occupational unemployment, which, as mentioned above, is a highly demanding test for us). The chi square tests in the last column show that the effect of RTI on redistribution preferences for individuals with low income is statistically significantly lower than for individuals with high income, without exceptions.

\section{Conclusions}

Current innovations in information technology involve a substantial employment risk for individuals holding routine occupations by facilitating the ease of automation. We find that individuals in routine occupations respond to this risk by demanding higher levels of redistribution as a means of nonmarket insurance. Even though technological change is widely considered to be a key occupational driver with large distributive effects, whether it influences the preferred level of redistribution has not been subject of inquiry in the comparative political economy literature thus far. Indeed, our analysis suggests that on average the routine task intensity of an occupation has a larger positive effect on the preferred level of redistribution than other risks described in the literature. We show our results to be robust to a large number of sensitivity tests.

In this article we also show that the degree of routine task intensity of an occupation becomes a particularly influential determinant of redistribution preferences when an individual has more to lose from automation, that is, when his or her income is higher. Even though richer individuals on average might favour lower levels of redistribution, the routine task intensity of their occupation becomes a more important determinant of their demand for redistribution. Our findings therefore offer an interesting counterpoint to the traditional Meltzer-Richard redistribution story. While recent increases in inequality in industrialized democracies may promote more anti-redistribution attitudes from the affluent, increasing levels of automation risk could mitigate these effects. Our results in fact suggest the possibility of cross-class coalitions in support of a redistributive welfare state between low-wage individuals in non-routine occupations and high-wage individuals holding routine occupations. This has potentially significant implications for our understanding of economic voting and insider-outsider politics in industrialized democracies.

This study's empirical work is built on survey data, rather than an experimental design where individuals could be randomly assigned to occupations. One might argue that individuals self-select into occupations, leading to possibly confounded causal interpretations of our results. This reasoning would imply that risk-averse persons who already have higher preferences for the provision of public insurance choose occupations less exposed to risk. Or it could be that individuals in routine occupations (with high redistribution preferences), lose their jobs because of automation, and move to non-routine occupations while keeping higher levels of preferred nonmarket 
protection. While these arguments point to interesting extensions of our research, it is important to mention that they predict a negative association between the degree of routine task intensity and the preferred level for redistribution, militating against this article's statistically significant findings of a positive association.

Finally, in this article we focus on the differences in automation risk (depending on the degree of routine task intensity) across occupations. We devote less attention to country-specific patterns like, for instance, the amount of investment in research and development, or qualitative educational factors that potentially shape how individuals cope with technological change. This would also be an interesting line of future inquiry. More generally, our analysis only begins to explore how technological risks shape actual redistribution and the welfare state. Future research should consider whether exposure to risk of automation affects voting behaviour, and party and policy agendas, and ultimately, actual welfare state policies. 


\section{References}

Ai, C., and E. C. Norton. 2003. "Interaction terms in logit and probit models." Economics Letters 80 (July): 123-129.

Alesina, A. F., and P. Giuliano. 2009. Preferences for redistribution. Technical report National Bureau of Economic Research.

Autor, D. H., and D. Dorn. 2013. "The Growth of Low-Skill Service Jobs and the Polarization of the US Labor Market." American Economic Review 103 (5): 1553-97.

Autor, D. H., D. Dorn, and G. H. Hanson. 2015. "Untangling Trade and Technology: Evidence from Local Labour Markets." The Economic Journal 125 (May): 621-646.

Autor, D. H., F. Levy, and R. J. Murnane. 2003. "The Skill Content of Recent Technological Change: An Empirical Exploration." The Quarterly Journal of Economics 118 (January): 1279-1333.

Benabou, R., and E. A. Ok. 2001. "Social Mobility and the Demand for Redistribution: The POUM Hypothesis." Quarterly Journal of Economics 116 (2).

Betz, H.-G. 1994. Radical right-wing populism in Western Europe. New York: St. Martin's Press.

Burgoon, B. 2014. "Immigration, Integration, and Support for Redistribution in Europe." World Politics 66 (July): 365-405.

Burgoon, B., F. Koster, and M. v. Egmond. 2012. "Support for redistribution and the paradox of immigration." Journal of European Social Policy 22 (July): 288-304.

Cusack, T., T. Iversen, and P. Rehm. 2006. "Risks at Work: The Demand and Supply Sides of Government Redistribution." Oxford Review of Economic Policy 22 (September): 365-389.

Dancygier, R., and S. Walter. 2015. The politics of advanced capitalism. Cambridge University Press chapter Globalization, labor market risks, and class cleavages.

Erikson, R., and J. Goldthorpe. 1992. The constant flux: A study of class mobility in industrial societies. Oxford: Clarendon Press.

Ford, M. 2015. Rise of the Robots: Technology and the Threat of a Jobless Future. Basic Books.

Frey, C. B., and M. A. Osborne. 2017. "The future of employment: how susceptible are jobs to computerisation?" Technological Forecasting and Social Change 114: 254-280.

Gingrich, J., and B. Ansell. 2012. "Preferences in Context Micro Preferences, Macro Contexts, and the Demand for Social Policy." Comparative Political Studies (October): 0010414012463904.

Goldin, C., and L. Katz. 2008. The race between education and technology: The evolution of U.S. educational wage differentials, 1890 to 2005. Cambridge: Harvard University Press. 
Goos, M., and A. Manning. 2007. "Lousy and Lovely Jobs: The Rising Polarization of Work in Britain." Review of Economics and Statistics 89 (February): 118-133.

Goos, M., A. Manning, and A. Salomons. 2014. "Explaining Job Polarization: RoutineBiased Technological Change and Offshoring." The American Economic Review 104 (August): 2509-2526.

Greene, W. 2010. "Testing hypotheses about interaction terms in nonlinear models." Economics Letters 107 (May): 291-296.

Grossman, G. M., and E. Rossi-Hansberg. 2008. "Trading Tasks: A Simple Theory of Offshoring." American Economic Review 98 (5): 1978-97.

Häusermann, S., T. Kurer, and H. Schwander. 2015. "High-skilled outsiders? Labor market vulnerability, education and welfare state preferences." Socio-Economic Review 13 (January): 235-258.

Hout, M. 2004. Getting the most out of the HSS income measures. Technical report GSS Methodological Report 101.

Iversen, T., and D. Soskice. 2001. "An asset theory of social policy preferences." American Political Science Review 95 (4): 875-893.

Iversen, T., and D. Soskice. 2009. "Distribution and Redistribution: The Shadow of the Nineteenth Century." World Politics 61 (July): 438-486.

Iversen, T., and T. R. Cusack. 2000. "The Causes of Welfare State Expansion: Deindustrialization or Globalization?” World Politics 52 (April): 313-349.

Katz, L. F., and K. M. Murphy. 1992. "Changes in Relative Wages, 1963-1987: Supply and Demand Factors." The Quarterly Journal of Economics 107 (1): 35-78.

Kitschelt, H., and P. Rehm. 2014. "Occupations as a Site of Political Preference Formation." Comparative Political Studies 47 (October): 1670-1706.

Kopczuk, W., E. Saez, and J. Song. 2010. "Earnings Inequality and Mobility in the United States: Evidence from Social Security Data Since 1937.” The Quarterly Journal of Economics 125 (January): 91-128.

Lichbach, M. I. 1989. "An evaluation of "does economic inequality breed political conflict?" studies." World Politics 41 (04): 431-470.

Lipset, S. M. 1960. Political man: The social basis of modern politics. New York: Doubleday.

Margalit, Y. 2011. "Ideology all the way down? The impact of the financial crisis on individuals welfare policy preferences." In Merton College University of Oxford political economy workshop.

Meltzer, A. H., and S. F. Richard. 1981. "A Rational Theory of the Size of Government." Journal of Political Economy 89 (October): 914-927.

Michaels, G., A. Natraj, and J. Van Reenen. 2014. "Has ICT Polarized Skill Demand? Evidence from Eleven Countries over Twenty-Five Years." Review of Economics and Statistics 96 (April): 60-77. 
Moene, K. O., and M. Wallerstein. 2001. "Inequality, Social Insurance, and Redistribution." The American Political Science Review 95 (December): 859-874.

Nelson, K. 2012. "Counteracting material deprivation: The role of social assistance in Europe." Journal of European Social Policy 22 (May): 148-163.

Nie, N. H., and J.-o. Kim. 1978. Participation and political equality: A seven-nation comparison. University of Chicago Press.

OECD. 2008. A profile of immigration populations in the 21st century: Data from OECD countries. Paris: OECD.

OECD. 2014a. Indicators of employment protection. Paris: OECD.

OECD. 2014b. PPPs and exchange rates. Paris: OECD.

OECD. 2014c. Tax-benefit models. Paris: OECD.

Oesch, D. 2006. "Coming to Grips with a Changing Class Structure An Analysis of Employment Stratification in Britain, Germany, Sweden and Switzerland." International Sociology 21 (January): 263-288.

Oesch, D. 2013. Occupational change in Europe: how technology and education transform the job structure. Oxford University Press.

Rehm, P. 2009. "Risks and Redistribution An Individual-Level Analysis." Comparative Political Studies 42 (January): 855-881.

Romer, D. 1990. "Endogenous technological change." Journal of Political Economy 98 (5): S71-S102.

Rommel, T., and S. Walter. 2014. "The political consequences of offshoring." In American Political Science Association.

Rosenstone, S. J., and J. M. Hansen. 1993. Mobilization, Participation and Democracy in America. New York: Macmillan.

Rueda, D. 2007. Social Democracy Inside Out: Partisanship and Labor Market Policy in Advanced Industrialized Democracies. Oxford: Oxford University Press.

Rueda, D. Forthcoming. "Food Comes First, Then Morals: Redistribution Preferences, Parochial Altruism and Immigration in Western Europe." The Journal of Politics.

Schwander, H., and S. Hausermann. 2013. "Who is in and who is out? A risk-based conceptualization of insiders and outsiders." Journal of European Social Policy 23 (3): 248-269.

Sinn, H.-W. 1995. "A theory of the welfare state." Scandinavian Journal of Economics 97 (4): 495-526.

Solt, F. 2014. The standardized world income inequality database. Technical report Working paper SWIID version 5.0.

Spitz-Oener, A. 2006. "Technical Change, Job Tasks, and Rising Educational Demands: Looking outside the Wage Structure.” Journal of Labor Economics 24 (April): 235270.

Thewissen, S. 2014. "Is it the income distribution or redistribution that affects 
growth?" Socio-Economic Review 12 (January): 545-571.

Walter, S. 2010. "Globalization and the Welfare State: Testing the Microfoundations of the Compensation Hypothesis." International Studies Quarterly 54 (June): 403426.

Walter, S. 2017. "Globalization and the Demand-Side of Politics: How Globalization Shapes Labor Market Risk Perceptions and Policy Preferences." Political Science Research and Methods 5 (1): 55,Äì80.

Wren, A. 2013. The political economy of the service transition. Oxford: Oxford University Press chapter Introduction: The political economy of post-industrial societies, pp. 1-70.

Wren, A., and P. Rehm. 2014. "The end of the consensus? Labour market developments and the politics of retrenchment." Socio-Economic Review 12 (January): 409-435. 


\section{A. Differences between Kitschelt and Rehm and the RTI index}

In this section we compare the Kitschelt and Rehm (2014) dummies based on Oesch (2006), which are meant to capture routine occupations, to the continuous RTI index from Goos et al. (2014) used in this article. We argue that the RTI index is substantively and empirically superior to the Kitschelt and Rehm (henceforth, KR) dummies if the objective is to examine the routine task intensity of occupations. First, the RTI index is continuous and provides significantly more variation across occupational groups. This holds even though the KR dummies are defined at the more detailed 4-digit ISCO-88 occupational level. Second, the KR dummies do not measure the degree of routine task intensity but follow educational and income lines. Third, we have more (5.6 per cent) observations at our disposal for the RTI index.

KR distinguish between four a groups which capture a vertical 'logic of authority' dimension (the degree of discretionary space): professionals, associate professionals, skilled routine, and unskilled routine. In addition, KR generate a second 'logic of tasks' dimension with three $t$ groups (capturing whether tasks are more or less clearly defined): organisational, technical, and interpersonal task logics. This dimension does not have any clear linkage with RTI. The four $a$ and three $t$ groups are combined and merged into four $c$ groups:

1. Skilled organisational: Professionals and associate professionals with an organisational logic of task structure, who are against redistribution;

2. Skilled technical: Professionals and associate professionals with a technical task structure, with more uncertainty and loose horizontal structures, who are less opposed to redistribution;

3. Skilled interpersonal: Professionals and associate professionals with interpersonal task structure, who accept redistribution;

4. Routine: The skilled and unskilled routine workers in all three aforementioned task structures are grouped here. This group is hypothesised to be in favour of redistribution.

Table 7 shows the mean values for all KR dummies for occupations at the 2-digit ISCO-88 level, where we sort occupations by their level of RTI. Only eight occupations at the 2-digit level for a groups and only four occupations for the $c$ groups are not fully captured by a dummy (marked in bold). Thus, the more detailed 4-digit level at which the KR dummies are defined barely produces additional variation at a more aggregated level. In fact, the variation is significantly decreased because of the dichotomous nature of the measures.

More importantly, substantively the KR dummies are intended to measure 'unskilled routine' (a4) or 'routine' groups (c4) as compared to 'authoritarian' (a1-3) or 'skilled' groups (c1-3) - not to demarcate routine from non-routine occupations. 
KR stress that they are interested in discretionary space rather than the intensity of routine tasks per occupation. The 'unskilled routine' group a4 captures all occupations whose ISCO-codes start with an 8 and 9 (plant and machine operators and assemblers, and elementary occupations), almost all occupations starting with a 5 and 6 (service workers and shop and market sales workers, and skilled agricultural and fishery workers for which we do not have RTI data), and parts of occupations starting with a 4 and 7 (clerks, and craft and related trades workers). The 'routine' $c 4$ group combines groups $a 3$ and $a 4$. It includes all occupations for which the ISCO-88 code begins between 4 and 9, thus all occupations except legislators, senior officials and managers, professionals, or technicians and associate professionals. This group is very large, containing a $28 \%$ larger sample size than the $c 1-c 3$ groups combined.

Groups $a 4$ and $c 4$ do not measure the degree of routine task intensity of occupations contrasted to non-routine abstract or manual task intensive occupations, but closely follow educational and income lines. We can see this in particular for group c4, which indeed contains all occupations with a positive RTI index, but also includes for instance occupations 51 (personal and protective services workers) and in particular 83 (drivers and mobile plant operators). As we argue and empirically show, it is not true that all low-skilled occupations are routine (Michaels et al., 2014; Goos et al., 2014). Moreover, as all KR categories are measured as dummies, they do not do justice to the fact that certain occupations are significantly more or less routine than others. The KR dummies distinguish among large groups that largely follow educational and income lines - this might include an element of RTI, but it will capture most certainly more, indeed all, (unobserved) differences in these groups.

\section{B. Multilevel probit results}

In this section, we present the results of our multilevel ordered probit models, with random country intercepts and standard errors clustered at the country level. As with our previous sensitivity tests, we show the results for the regressions with all control variables included, both with and without the interaction variable, in Table 8 . The sign and size of coefficients for our variables of interest are all very comparable. This also holds for the control variables.

\section{Unobserved variation across and within occupations}

There might be differences (other than risks) across individuals sorted in particular occupations. Some of these differences are accounted for in our estimations, by including control variables that vary at the occupational level. In this appendix we further explore whether unobserved heterogeneity across occupations affects our main results. 
Table 7: Comparing RTI index to the Kitschelt and Rehm classification

\begin{tabular}{|c|c|c|c|c|c|c|c|c|c|c|c|c|}
\hline \multirow[b]{3}{*}{ ISCO } & \multirow[b]{3}{*}{ RTI } & \multirow{2}{*}{\multicolumn{4}{|c|}{$\begin{array}{c}\text { Logic of authority groups } \\
\text { Professionals (a1), } \\
\text { Associate profess. (a2), } \\
\text { Skilled routine (a3), } \\
\text { Unskilled routine (a4) }\end{array}$}} & \multirow{2}{*}{\multicolumn{3}{|c|}{$\begin{array}{c}\text { Logic of tasks groups } \\
\text { Organisational (t1), } \\
\text { Technical (t2), } \\
\text { Interpersonal (t3) }\end{array}$}} & \multirow{2}{*}{\multicolumn{4}{|c|}{$\begin{array}{l}\text { Combined groups } \\
\text { a1t1 + a2t1 (c1), } \\
\text { a1t2 + a2t2 (c2), } \\
\text { a1t3 + a2t3 (c3), } \\
+ \text { a4 all t-groups (c4) }\end{array}$}} \\
\hline & & & & & & & & & & & & \\
\hline & & a1 & a2 & a3 & a4 & $\mathrm{t} 1$ & $\mathrm{t} 2$ & $\mathrm{t} 3$ & $\mathrm{c} 1$ & $\mathrm{c} 2$ & c3 & c4 \\
\hline 13 & -1.52 & 0.00 & 1.00 & 0.00 & 0.00 & 1.00 & & & & & & \\
\hline 83 & -1.50 & 0.00 & 0.00 & 0.53 & 0.47 & 0 & & & & & & \\
\hline 22 & -1.00 & 1.00 & 0.00 & & 0.00 & & & & & & & \\
\hline 21 & -0.82 & 1.00 & 0.00 & 0.00 & 0.00 & 0 & & & & & & \\
\hline 12 & -0.75 & 1.00 & 0.00 & 0.00 & 0.00 & & & & & & & \\
\hline 24 & -0.73 & & & & 0.00 & & & & & & & 0.00 \\
\hline 51 & -0.60 & & 0.00 & & 0.70 & & & & 00 & & & 1.00 \\
\hline 34 & -0.44 & & 1.00 & & 0.00 & & & & 79 & & & 0.00 \\
\hline 31 & -0.40 & & 1.00 & & & & & & 00 & & & 0.00 \\
\hline 32 & -0.3 & & & & & & & & 00 & & & 0.11 \\
\hline 71 & -0 . & & & & & & & & 00 & & & 1.00 \\
\hline 91 & & & & & & & & & 00 & & & 1.00 \\
\hline 52 & & & & & 0.98 & & & & 00 & & & 1.00 \\
\hline 81 & & & & & 1.0 & & & & 00 & & & 1.00 \\
\hline 93 & & & & & 1.0 & & & & 00 & & & 1.00 \\
\hline 72 & & & & & 0.0 & & & & 00 & & & 1.00 \\
\hline 82 & & & & 0.00 & 1.0 & & & & 00 & & 0.00 & 1.00 \\
\hline 74 & & & 0.00 & & 0.0 & & & & 00 & & 0.00 & 1.00 \\
\hline 42 & 1. & & 0.00 & 0.24 & 0.76 & & & & 0.00 & & 0.00 & 1.00 \\
\hline 73 & & & 0.00 & 1.00 & 0.0 & 0.00 & & & 0.00 & & 0.00 & 1.00 \\
\hline 41 & 2.24 & 0.00 & 0.00 & 0.93 & 0.07 & 1.00 & 0.00 & 0.00 & 0.00 & 0.00 & 0.00 & 1.00 \\
\hline
\end{tabular}

The first test that we conduct is the inclusion of occupational dummies. Our main RTI measure is country and time invariant, and is measured at the 2-digit occupational level. In order to identify the model, we can only include dummies for 1-digit occupations which contain enough variation across the less aggregated 2-digit occupational groups. Since there are relatively few groups in our data, this is a very stringent test. As can be seen in Table 1, the RTI measure contains eight 1-digit occupational groups (as data for group 6 are missing). Four of the 1-digit groups (groups 1, 4, 5, and 9) contain two 2-digit groups; three 1-digit groups (groups 2, 3 , and 8) have data for three 2-digit groups, and one 1-digit group (group 7) has information for four 2-digit groups. Column (1) in Table 9 shows that our results are replicated if we include dummies for the four 1-digit occupational groups that contain at least three 2-digit occupational groups. The RTI coefficient decreases somewhat from 0.042 in our main results to 0.035 .

As a second alternative to probing whether our results are sensitive to occupational selection, we separate our sample into non-routine and routine occupations. This allows us to assess whether relative levels of RTI affect redistribution preferences 
Table 8: Multilevel probit results

\begin{tabular}{|c|c|c|}
\hline & $\begin{array}{c}(1) \\
\text { Without interaction }\end{array}$ & $\begin{array}{c}(2) \\
\text { With interaction }\end{array}$ \\
\hline RTI & $\begin{array}{c}0.042 * * * \\
(0.000)\end{array}$ & $\begin{array}{c}0.043 * * * \\
(0.000)\end{array}$ \\
\hline Income & $\begin{array}{c}-0.184 * * * \\
(0.000)\end{array}$ & $\begin{array}{c}-0.177 * * * \\
(0.000)\end{array}$ \\
\hline $\mathrm{RTI} *$ income & & $\begin{array}{c}0.024 * * * \\
(0.003)\end{array}$ \\
\hline Years of education & $\begin{array}{c}-0.023 * * * \\
(0.000)\end{array}$ & $\begin{array}{l}-0.023 * * * \\
(0.000)\end{array}$ \\
\hline Male & $\begin{array}{c}-0.212 * * * \\
(0.000)\end{array}$ & $\begin{array}{c}-0.211 * * * \\
(0.000)\end{array}$ \\
\hline Age & $\begin{array}{c}0.003 * * * \\
(0.003)\end{array}$ & $\begin{array}{c}0.003 * * * \\
(0.003)\end{array}$ \\
\hline Trade union member & $\begin{array}{l}0.181 * * * \\
(0.000)\end{array}$ & $\begin{array}{l}0.181 * * * \\
(0.000)\end{array}$ \\
\hline Degree of religiosity & $\begin{array}{l}-0.010 * * * \\
(0.006)\end{array}$ & $\begin{array}{c}-0.010 * * * \\
(0.006)\end{array}$ \\
\hline Unemployed & $\begin{array}{c}0.170 * * * \\
(0.000)\end{array}$ & $\begin{array}{c}0.172 * * * \\
(0.000)\end{array}$ \\
\hline Lag of social spending & $\begin{array}{l}-0.004 \\
(0.497)\end{array}$ & $\begin{array}{c}-0.004 \\
(0.494)\end{array}$ \\
\hline Lag of unemployment & $\begin{array}{c}0.008 \\
(0.492)\end{array}$ & $\begin{array}{c}0.008 \\
(0.496)\end{array}$ \\
\hline Log pseudolikelihood & $-8.5 e+04$ & $-8.5 e+04$ \\
\hline Country variance & $0.143 * * *$ & $0.143 * * *$ \\
\hline $\mathrm{N}$ & 64639 & 64639 \\
\hline Number of countries & 17 & 17 \\
\hline
\end{tabular}


within the non-routine and routine categories. For the identification of the main effect, we therefore rely on the variation in RTI across 2-digit occupational groups within non-routine occupations or within routine occupations. At first sight, this seems to have consequences for our main results.

In column (2) the sample is restricted to non-routine occupations (defined as those with a negative RTI score). The RTI coefficient is positive and the coefficient increases substantially from 0.042 to 0.062 . In column (3), only routine occupations are included. The routine sample is only half as large as the non-routine sample. Instead of a positive RTI coefficient, we now find a negative coefficient that is significant at the 5 per cent level. This suggests that within routine occupations, those with higher RTI demand less redistribution than those with lower RTI. This runs counter to our main results. In column (4) we show that this counterintuitive result becomes insignificant when occupation 41, office clerks, are excluded. The office clerks are a particular group for two reasons. First, they are large and therefore influential ( $8.7 \%$ in our total sample and the largest routine group). Second, they have on average fairly high redistribution preferences (3.78 compared to 3.86 of individuals in routine occupations excluding office clerks and 3.57 for non-routine occupations), but they combine this with a very high RTI score (2.24, whereas the second-most routine are precision workers with a score of 1.59 and this difference is much larger than within the non-routine occupational groups). Indeed, as we show in column (5), using the full sample except office clerks boosts the coefficient for RTI from 0.042 to 0.07338

Finally, as we stated in footnote 32 in the main text, leaving out countries, years, or occupations one by one does not affect our results. The RTI coefficient varies between 0.032-0.073 in size when occupational groups are excluded one by one, and dropping countries (0.038-0.045) or waves (0.039-0.045) has minimal effects.

While we recognize that unobserved variation across and within occupations is an important issue not only for this article but for other analyses in this literature, it is unclear that using occupational dummies is the right strategy. Given the occupational nature of the RTI measure, it is inevitable that occupational dummies will affect the estimation of its effects. Incidentally, this is also the case with other occupational factors like skill specificity, which becomes insignificant when including the five 1-digit dummies in column (1). We should be cautious when interpreting these results.

\footnotetext{
${ }^{38}$ We also ran these tests with the Frey and Osborne occupational coding, which has more variation within the 1-digit occupational groups. Results are comparable to those presented here, the only difference being that the index becomes insignificant when we focus on the routine group.
} 
Table 9: Occupational dummies and splitting the sample

\begin{tabular}{|c|c|c|c|c|c|}
\hline & $\begin{array}{l}\text { (1) } \\
\text { With dummies }\end{array}$ & $\begin{array}{c}\text { (2) } \\
\text { Non-routine } \\
\text { sample }\end{array}$ & $\begin{array}{l}\text { (3) } \\
\text { Routine } \\
\text { sample }\end{array}$ & $\begin{array}{l}\text { (4) } \\
\text { Routine sample } \\
\text { excl. } 41\end{array}$ & $\begin{array}{l}\text { (5) } \\
\text { Full sample } \\
\text { excl. } 41\end{array}$ \\
\hline RTI & $\begin{array}{c}0.035 * * * \\
(0.000)\end{array}$ & $\begin{array}{c}0.062^{* * *} \\
(0.000)\end{array}$ & $\begin{array}{c}-0.022 * * \\
(0.030)\end{array}$ & $\begin{array}{c}-0.016 \\
(0.348)\end{array}$ & $\begin{array}{c}0.073 * * * \\
(0.000)\end{array}$ \\
\hline Income & $\begin{array}{c}-0.172 * * * \\
(0.000)\end{array}$ & $\begin{array}{c}-0.191 * * * \\
(0.000)\end{array}$ & $\begin{array}{c}-0.124^{* * * *} \\
(0.000)\end{array}$ & $\begin{array}{l}-0.129 * * * \\
(0.000)\end{array}$ & $\begin{array}{c}-0.183 * * * \\
(0.000)\end{array}$ \\
\hline Years of education & $\begin{array}{c}-0.017 * * * \\
(0.000)\end{array}$ & $\begin{array}{c}-0.023^{* * *} \\
(0.000)\end{array}$ & $\begin{array}{c}-0.012^{* * *} \\
(0.000)\end{array}$ & $\begin{array}{c}-0.013 * * * \\
(0.001)\end{array}$ & $\begin{array}{c}-0.022 * * * \\
(0.000)\end{array}$ \\
\hline Male & $\begin{array}{l}-0.241 * * * \\
(0.000)\end{array}$ & $\begin{array}{c}-0.243^{* * *} \\
(0.000)\end{array}$ & $\begin{array}{c}-0.151^{* * *} \\
(0.000)\end{array}$ & $\begin{array}{c}-0.163 * * * \\
(0.000)\end{array}$ & $\begin{array}{c}-0.219 * * * \\
(0.000)\end{array}$ \\
\hline Age & $\begin{array}{l}0.003 * * \\
(0.011)\end{array}$ & $\begin{array}{l}0.003 * * * \\
(0.005)\end{array}$ & $\begin{array}{l}0.003 * * * \\
(0.009)\end{array}$ & $\begin{array}{l}0.004 * * * \\
(0.001)\end{array}$ & $\begin{array}{c}0.003 * * * \\
(0.005)\end{array}$ \\
\hline Trade union member & $\begin{array}{l}0.171^{* * *} \\
(0.000)\end{array}$ & $\begin{array}{l}0.203 * * * \\
(0.000)\end{array}$ & $\begin{array}{l}0.110 * * * \\
(0.000)\end{array}$ & $\begin{array}{l}0.105^{* * *} \\
(0.000)\end{array}$ & $\begin{array}{l}0.181^{* * *} \\
(0.000)\end{array}$ \\
\hline Degree of religiosity & $\begin{array}{l}-0.008 * * \\
(0.020)\end{array}$ & $\begin{array}{l}-0.009 * * \\
(0.021)\end{array}$ & $\begin{array}{l}-0.007 * \\
(0.057)\end{array}$ & $\begin{array}{l}-0.007 \\
(0.119)\end{array}$ & $\begin{array}{c}-0.009 * * \\
(0.026)\end{array}$ \\
\hline Unemployed & $\begin{array}{l}0.128 * * * \\
(0.000)\end{array}$ & $\begin{array}{l}0.153 * * * \\
(0.000)\end{array}$ & $\begin{array}{l}0.111^{* * * *} \\
(0.000)\end{array}$ & $\begin{array}{l}0.096 * * * \\
(0.000)\end{array}$ & $\begin{array}{l}0.123 * * * \\
(0.000)\end{array}$ \\
\hline Lag of social spending & $\begin{array}{l}-0.004 \\
(0.506)\end{array}$ & $\begin{array}{l}-0.001 \\
(0.842)\end{array}$ & $\begin{array}{l}-0.012 * * \\
(0.030)\end{array}$ & $\begin{array}{l}-0.015 * * * \\
(0.004)\end{array}$ & $\begin{array}{l}-0.004 \\
(0.467)\end{array}$ \\
\hline Lag of unemployment & $\begin{array}{c}0.006 \\
(0.563)\end{array}$ & $\begin{array}{c}0.006 \\
(0.619)\end{array}$ & $\begin{array}{c}0.009 \\
(0.304)\end{array}$ & $\begin{array}{c}0.008 \\
(0.270)\end{array}$ & $\begin{array}{c}0.005 \\
(0.587)\end{array}$ \\
\hline Dummy group 2 & $\begin{array}{l}-0.064 * * \\
(0.026)\end{array}$ & & & & \\
\hline Dummy group 3 & $\begin{array}{l}-0.033 \\
(0.124)\end{array}$ & & & & \\
\hline Dummy group 7 & $\begin{array}{c}0.093 * * * \\
(0.000)\end{array}$ & & & & \\
\hline Dummy group 8 & $\begin{array}{c}0.160 * * * \\
(0.000)\end{array}$ & & & & \\
\hline Log pseudolikelihood & $-0.2 \mathrm{e} 10+4$ & $-6.1 e 10+4$ & $-3.1 \mathrm{e} 10+4$ & $-2.4 \mathrm{e} 10+4$ & $-8.5 e 10+4$ \\
\hline Country variance & $0.106 * * *$ & $0.118 * * *$ & $0.099 * * *$ & $0.092 * * *$ & $0.105^{* * *}$ \\
\hline $\mathrm{N}$ & 64639 & 42144 & 22495 & 16903 & 59047 \\
\hline Number of countries & 17 & 17 & 17 & 17 & 17 \\
\hline
\end{tabular}

